\title{
Lengua y artefactos en la etnografía wichí de Alfred Métraux
}

Langues et artefacts dans l'ethnographie wichí d'Alfred Métraux

Language and artefacts in Alfred Métraux's Wichí ethnography

\section{Rodrigo Montani}

\section{(2) OpenEdition}

Journals

\section{Edición electrónica}

URL: https://journals.openedition.org/jsa/14815

DOI: $10.4000 /$ jsa. 14815

ISSN: $1957-7842$

Editor

Société des américanistes

Edición impresa

Fecha de publicación: 31 diciembre 2016

Paginación: 75-97

ISSN: 0037-9174

Referencia electrónica

Rodrigo Montani, «Lengua y artefactos en la etnografía wichí de Alfred Métraux», Journal de la Société des américanistes [En línea], 102-2 | 2016, Publicado el 26 enero 2017, consultado el 03 septiembre 2022. URL: http://journals.openedition.org/jsa/14815 ; DOI: https://doi.org/10.4000/jsa. 14815

All rights reserved 


\title{
Lengua y artefactos en la etnografía wichí de Alfred Métraux
}

\author{
Rodrigo MONTANI *
}

\begin{abstract}
Para evaluar el lugar que ocuparon la lengua nativa y los artefactos en la producción etnográfica de Métraux sobre los wichís del Gran Chaco se revisan sus publicaciones y algunos textos inéditos. Con sólo ojear su capítulo chaqueño para el Handbook of South American Indians o con recordar las colecciones que ingresó en diferentes museos, queda de manifiesto que la cultura material wichí tuvo en su obra una importancia decisiva. No sucede lo mismo con la lengua wichí. Por eso aquí se presenta una versión acondicionada y traducida del mito de « Pájaro Carpintero y la hija de Sol » que Métraux recogió en el terreno y dejó inédita, junto con otras historias, en una de sus libretas de campo; y se discute brevemente cuál es el valor de esta « nueva » versión del mito. [Palabras clave: Métraux, mataco-mataguayo, cultura material, lengua wichí, mitología.]
\end{abstract}

Langues et artefacts dans l'ethnographie wichi d'Alfred Métraux. Afin d'évaluer l'importance qu'eurent la langue vernaculaire et les objets dans la production ethnographique de Métraux sur les Wichí du Gran Chaco, on examine ses publications et plusieurs écrits inédits. S'il suffit de regarder sa contribution sur le Chaco dans le Handbook of South American Indians et les collections qu'il a réunies dans divers musées pour mesurer l'importance décisive de la culture matérielle wichí dans son œuvre, il n'en va pas de même pour la langue. C'est pourquoi on présente ici une version éditée et traduite du mythe «Pic et la fille de Soleil» laissée inédite par Métraux, et on évalue brièvement la valeur de cette " nouvelle » version du mythe. [Mots-clés: Métraux, Mataco-Mataguayo, culture matérielle, langue wichí, mythologie.]

Language and artefacts in Alfred Métraux's Wichí ethnography. Alfred Métraux's publications and some unpublished writings are reviewed in order to assess the place of native language and artifacts in his ethnographic works on the Wichí people of the Gran Chaco. A mere gaze at his "Ethnography of the Chaco » in the Handbook of South American Indians or the Wichí collections he provided for different museums, show that Wichíi material culture played a crucial role in Métraux's research. The same cannot be said of Wichí language. This is precisely

* Conicet, Argentina [rodrigomontani@hotmail.com]. 
why an edited and translated version of the myth of « Woodpecker and the daughter of Sun », which Métraux collected during his fieldwork and left unpublished in his field notebooks alongside others stories, is presented. Finally, the importance of this «new » version of the myth is briefly discussed. [Key words: Métraux, Matacoan, material culture, Wichí language, mythology.]

La etnografía wichí de Alfred Métraux es fruto de su afán por documentar con detalle y urgencia un mundo que, a sus ojos, en pocos años desaparecería. En la agenda histórico-difusionista que heredó voluntariamente de Nordenskiöld ${ }^{1}$, los chaqueños en general, y los wichí o « matacos » en particular, ocupaban un lugar comparativo importante: representaban « un tipo muy arcaico de cultura », un relicto de elementos antiguos de las regiones colindantes e incluso de un antiguo «sustrato » americano ${ }^{2}$. La etnografía wichí del suizo tuvo varios condimentos: la etnohistoria (Métraux 1929a, 1946), la economía (Métraux 1944b, 1946), el ciclo vital (Métraux 1944a), la apología de las misiones anglicanas (Métraux 1933b), las « epidemias de suicidio » en esas misiones (Métraux 1943; 1973, p. 142-154); pero también es cierto que en ella la tarea de documentar la cultura nativa fue constante $y$, en última instancia, la lengua y los artefactos fueron sus elementos centrales.

Descontando un primer contacto iniciático durante un viaje en 1922 (Métraux 1988, p. 65-66), Métraux realizó trabajo de campo con los wichís en tres oportunidades. En la expedición a los chiriguanos, de 1929, recorrió también algunos asentamientos de los wichís occidentales (Métraux 1931, p. 122 , 129). Cuando en 1933 viajó a los toba-pilagás, aprovechó las demoras fortuitas del viaje para trabajar con los wichís de Misión Chaqueña El Algarrobal y de Las Lomitas (Métraux 1939, p. 1). Pero recién se planteó la etnografía wichí como un objeto prioritario y explícito en 1937, cuando proyectaba su última expedición al Chaco ${ }^{3}$, que concretaría dos años más tarde visitando a los wichís de Embarcación, El Algarrobal, El Yuto, San Andrés y San Patricio, y que narraría en sus diarios (Métraux 1978, p. 57-90, 107-110).

Si el suizo se vinculó con estos indígenas practicando una etnografía « de salvataje », su primera actividad, podríamos decir « nordenskiöldiana », fue

1. En 1928 Métraux creó el Museo del Instituto de Etnología en la Universidad Nacional de Tucumán bajo la necesidad imperiosa de emprender una etnografía « de salvataje » para el Chaco. Así se desprende del «Plan acerca de la creación de un museo etnográfico en la provincia de Tucumán » que remitió a la Universidad Nacional de Tucumán en junio de 1928 (reproducido en Bilbao 2002, p. 28-31), que signaría toda su antropología chaqueña (véase, por ejemplo, Métraux 1937 en Bilbao 2002, p. 85-86; Métraux 1944b, p. 7; y también Arenas 1998; Bossert y Villar 2007).

2. Las expresiones figuran en el plan de trabajo con el que Métraux solicitó en 1937 una beca de la Fundación Guggenheim (reproducido en Bilbao 2002, p. 84-86).

3. Véase el plan de trabajo antes mencionado (Bilbao 2002, especialmente p. 85). 
comprar « los recuerdos tangibles del pasado » (Métraux 1929b, p. 437) - armas, herramientas, artesanías, materias primas, objetos en construcción. La meta era engrosar las colecciones de diferentes museos: « su » museo en Tucumán, el musée de l'Homme, el American Museum of Natural History, el Peabody Museum of Archaeology and Ethnology. Además, por documentos inéditos y publicados sabemos que buena parte de su trabajo de campo consistía no sólo en coleccionar « industrias » y mitos, sino también, siguiendo las enseñanzas de Marcel Mauss, en vincularlos con las demás esferas de la vida social: la economía, la organización social, la religión, el ritual, las terminologías (Figura 1, página siguiente) ${ }^{4}$.

Esta metodología de campo armonizaba con sus intereses como autor. Así, por ejemplo, publicó varios estudios de la mitología wichí (Métraux 1935a; 1973, p. 101-141), el más importante de los cuales es Mitos y cuentos de los indios matacos (Métraux 1939) ${ }^{5}$. Y si bien es cierto que jamás consagró un escrito íntegro a la cultura material wichí - como sí hizo, por ejemplo, con la de los chiriguanos y de los guaraníes en general (Métraux 1928, 1930) -, también lo es que ella ocupó en su obra un lugar importante. Basta repasar su monumental « Etnografía del Chaco » en el Handbook (Métraux 1946, 1944b). De las dieciséis secciones que forman la parte etnográfica del estudio, nueve versan sobre aspectos íntimamente vinculados con la « civilización material »: « actividades de subsistencia », « animales domesticados », « casas y aldeas », « mobiliario », " vestimenta y ornamentos », etc. Y de los setenta artefactos dibujados que la ilustran, diecinueve corresponden a los wichís ${ }^{6}$. Por otro lado, sus descripciones de artefactos son muy minuciosas y precisas. Por citar sólo un ejemplo: aunque en los últimos años se ha escrito mucho sobre la cultura material wichí (Alvarsson 1988, 2012; Arenas 2003; Gonzalo 1998; Montani 2012), las páginas que Métraux (1946, p. 256-260) dedicó a las trampas de caza serán probablemente por siempre una referencia obligada sobre el tema.

En la etnografía wichí del suizo, esta inclinación por « las cosas » responde a diversas razones, que Bossert y Villar (2007) apuntaron ya para el caso chiriguano. Recoger y describir objetos tradicionales era algo relativamente sencillo $^{7}$, y además, como éstos pronto desaparecerían ${ }^{8}$, era para él una especie

4. Refiriéndose a su viaje al Chaco de 1939, por ejemplo, declara: « Hice investigaciones sociológicas en conexión con estudios en otros campos tales como economía y tecnología » (carta de A. Métraux al Sr. Moe, 13/01/1940; en Bilbao 2002, p. 93; véase también Métraux 1944a, p. 7). Un buen ejemplo de las preocupaciones sobre la cultura material en el terreno es la libreta FAM.AS.MT.02.12, « Matako San Patricio » (31 julio-1º agosto 1939), LAS, Collège de France, CNRS y EHESS.

5. Las traducciones de títulos y citas originalmente en inglés y francés son mías.

6. Métraux 1946, figuras 26, 27, 28, 32, 33, 36, 40, 42.

7. Escribió Métraux: « la cultura material [está] abierta a todos » (1944a, p. 7).

8. «Me preocupé particularmente por coleccionar tantos artefactos como pude ya que sé que mi viaje es probablemente la última oportunidad que un científico tiene de hacer una 


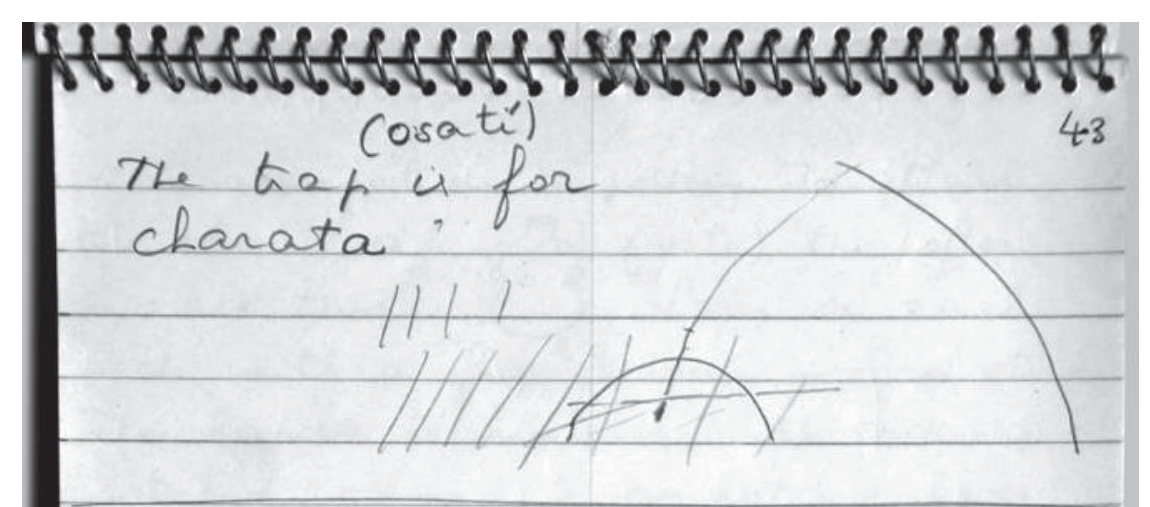

The trap

crien of

sticks

rests on 2 sticks

jomid like tha $\rightarrow$ H

a conde is stetched

wise from th stick to th two conner of the trap.

This kap is for prigeons Neme osat.

Food: Eat pop.corn.

sole have foroto de monte

(emgist)

Fig. 1 - Dibujos de trampas en una libreta de campo de A. Métraux (FAM.AS.MT.02.12_045 (C) Collège de France.

Archives Laboratoire d'anthropologie sociale/Fonds Métraux). 
de obligación moral ${ }^{9}$. Además, resultaba más fácil coleccionar artefactos « auténticos » que rasgos de conducta, más aún cuando se trabajaba - como él creía - con un pueblo « degenerado », « aculturado » o " amorfo » (por ejemplo, Métraux 1933a, p. 203). Finalmente, la cultura material era una pista privilegiada para resolver el problema que le había legado Nordenskiöld, y también el padre John Cooper (Rivière 2010, p. 154; Wagley 1964, p. 603-604): la reconstrucción de la historia cultural americana - o si se quiere pensar en un legado maussiano, el estudio de los fenómenos de civilización. Más tarde, de hecho, estos mismos artefactos le servirían para darle a su etnología el tinte ecológico-cultural del Handbook. Estas tres razones también explican, en líneas generales, el interés de Métraux por los mitos, que son una suerte de objetos verbales. Y me atrevo a arriesgar una razón adicional. En aquella entrevista que le hicieran dos años antes de su suicidio, Métraux decía: « me he sentido extremadamente cómodo [entre los pueblos de Sudamérica...] Tal vez porque percibí a mi alrededor un ritmo más lento, porque los seres con los que trataba no sufrían los problemas que nos abruman a todos, y esto era para mí una especie de sosiego » (en Bing 1964, p. 21). Sospecho, pues, que ese ritmo demorado y esa suerte de calma existencial los encontró en el Chaco, estudiando los objetos: ellos mueren, al fin de cuentas, con menor rapidez que los hombres (Figura 2, página siguiente).

Pero dejemos las especulaciones para abordar la pregunta que falta: ¿qué lugar ocupa la lengua nativa en la etnografía wichí de Alfred Métraux? En principio, uno bien reducido. Aun siendo un investigador polígloto y enterado de fonética ${ }^{10}$, que logró insertar en su compilación de narrativa wichí (Métraux 1939) varios nombres indígenas de plantas, animales y divinidades, todo indica que relevó esos textos en español. Sabemos que por entonces « Métraux no conoce la lengua mataca »- tal como informa un ingrato Jules Henry a Ruth Benedict, potencial editora de esos mismos Mitos y cuentos... en el Journal of American Folk-Lore ${ }^{11}$. Años más tarde, en San Andrés, el propio interesado lo confirma en sus diarios: «Me parece que jamás aprenderé esta lengua [wichí], e incluso que si la aprendiera el esfuerzo no valdría la pena » (Métraux 1978, p. 82). Es, entonces, momento de presentar un dato nuevo.

colección completa de la cultura material del Chaco ", dice Métraux en una carta enviada desde el terreno, el $1^{\circ}$ de agosto de 1939, a la Fundación Guggenheim (en Bilbao 2002, p. 90).

9. Un « deber sagrado », asegura, por ejemplo, en el mencionado « Plan acerca de la creación de un museo etnográfico... » (en Bilbao 2002, p. 28; cf. Arenas 1998, p. 125).

10. En 1925 se había graduado en la École nationale des langues orientales vivantes (Bilbao 2002, p. 254; Rivière 2010, p. 151).

11. Carta de Jules Henry a Ruth Benedict, 01/10/1937, Archives and Special Collections, Vassar College. Benedict, Ruth, box 29.5. 


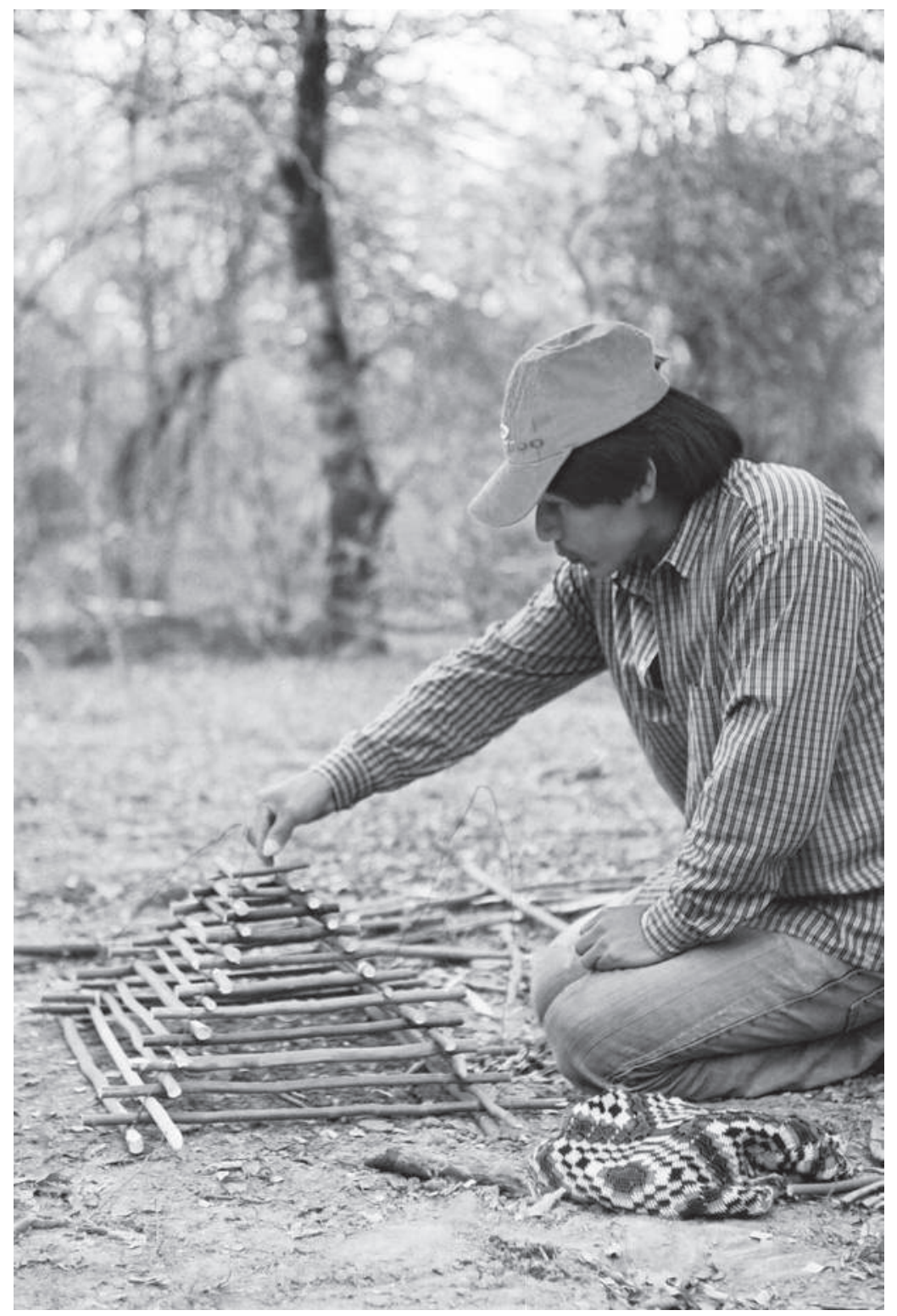

Fig. 2 - Juan Carlos Pino construyendo una trampa t'uphyen, para pájaros; Los Baldes, 22/08/2008. Foto del autor. 


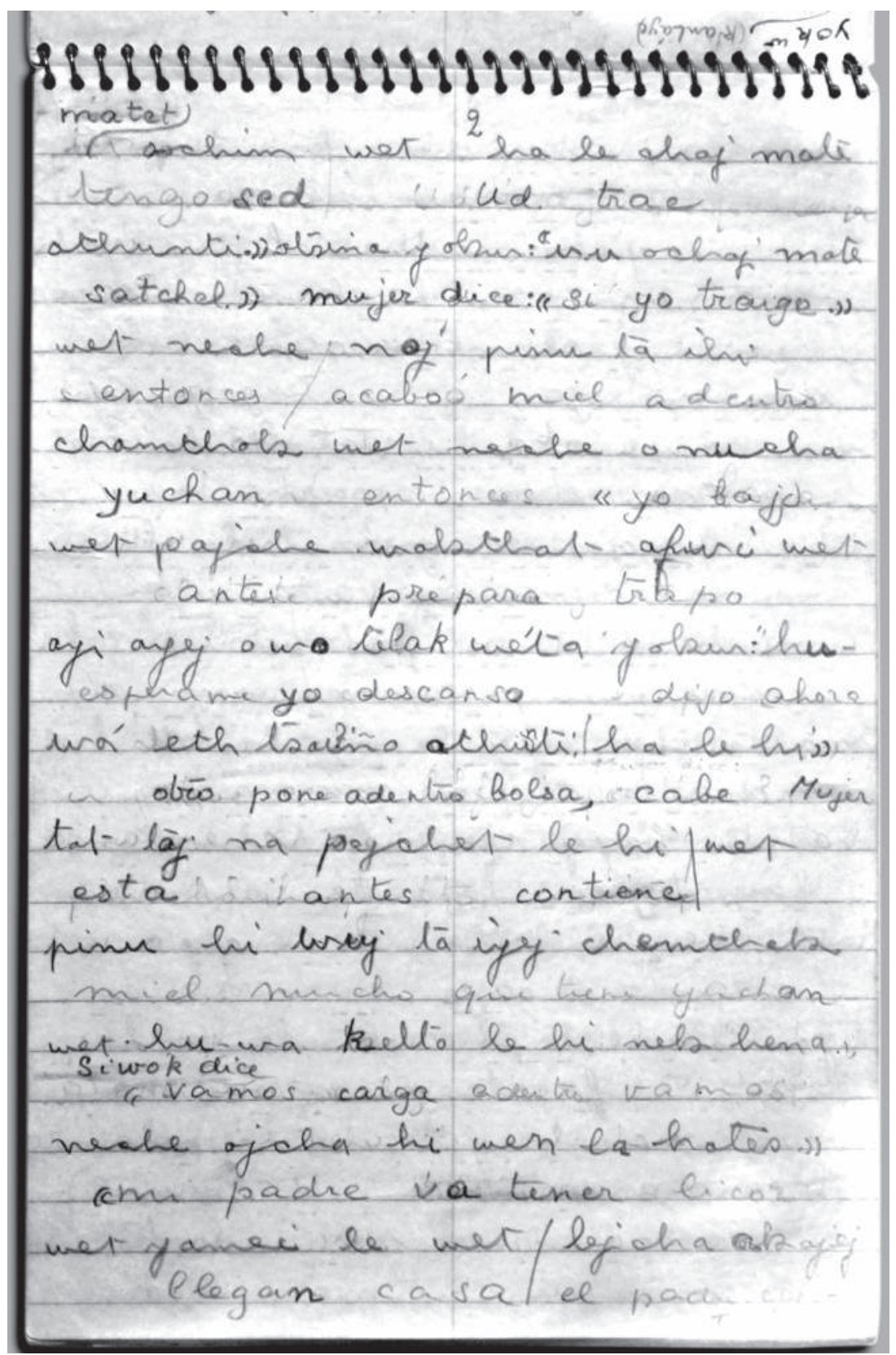

Fig. 3 - Una página del mito de « Pájaro Carpintero y la hija de Sol» anotado por A. Métraux (FAM.AS.MT.02.09_006 (C) Collège de France. Archives Laboratoire d'anthropologie sociale/Fonds Métraux). 
Una de las libretas del suizo que conserva el Laboratoire d'anthropologie sociale (LAS) en París, rotulada " Misión Pilaga (1939) 12 », no contiene nada que concierna a los pilagás. Hay, en cambio, una primera página con nombres castellanos y algunos términos de parentesco en wichí, y otras 49 páginas con líneas en esta lengua, intercaladas con líneas de traducción: son mitos ${ }^{13}$. Quiero concentrarme en las primeras 137 líneas que componen el primer relato. Métraux lo tituló « Historia de Tokwi[?]fwaj », es decir, de Tokwaj, Tío Travieso, el trickster de la mitología wichí. Pero en rigor se trata de una variante wichí de « La historia de la chica loca por la miel... », tal como la etiquetó LéviStrauss (1971, p. 87 y s.). Más concretamente, se trata de una versión de la historia wichí de « Pájaro Carpintero y la hija de Sol », historia en la que Tío Travieso suele desempeñar un papel secundario - $\mathrm{o}$, en la versión que trato, absolutamente marginal.

En un comienzo, la versión tiene una traducción aceptable al inglés ${ }^{14}$.

$2 \mathrm{~b}$. There was once time a man Tokwfwaj and this a

$3 \mathrm{~b}$. man called "Sun" and they were looking

$4 \mathrm{~b}$. for honey and they came, and his daughter got up and

$5 \mathrm{~b}$. (said): "Father, quiek hurry" and he spoke to his daughter

6 b. "Since I came you are worrying me

Pero a partir de la línea 11 el interlineado comienza a estar mayormente en español y se vuelve extraño:

$11 \mathrm{~b}$. (the woman asked) pregunta al pajarito cami[?] fuera[?]

$12 \mathrm{~b}$. si[?] se va se va hasta Tokw? xwax

$13 \mathrm{~b}$. (he) (look here) yo soy Siwok entonces otros

14 b. (dicen) dejala Ud. no es Siwok ${ }^{\mathrm{w}}$ entonces

15 b. otro dice "vaya este Siwok

12. FAM.AS.MT.02.09, LAS, Collège de France, CNRS y EHESS.

13. De las otras cuatro libretas de Métraux conservadas en el LAS que corresponden a los wichís, hay una sola que aún no pude consultar (FAM.AS.MT.02.04), que es precisamente la que también podría contener mitos.

14. Coloqué a cada línea wichí del manuscrito números correlativos del 1 al 137. Analicé cada línea así numerada en cinco líneas subordinadas: las líneas a y b muestran, respectivamente, la anotación wichí y la traducción de Métraux; la línea c presenta el texto wichí acondicionado (transliterado a mi alfabeto y puntuado) y segmentado morfema a morfema; la línea d ofrece el glosado de los morfemas, y finalmente la línea e presenta mi propia traducción. Un signo de interrogación entre corchetes señala una duda en mi lectura del manuscrito, en el análisis gramatical, el glosado o la traducción. 
Cabe aclarar que Siwok o Siwokw ${ }^{w}$ o en mi notación Siwokw, es el nombre wichí del protagonista de la historia y del prototipo del siwokw: el carpintero lomo blanco, Campephilus leucopogon (Figura 4, página siguiente) ${ }^{15}$.

A partir de la línea 16 encontramos un interlineado más difícil de seguir, compuesto de palabras sueltas, escasamente puntuadas, con muchos términos indígenas sin traducir, o bien traducidos imprecisa o hasta erróneamente ${ }^{16}$ :

16 b. atrás yuchan mujer

17 b. llega / entonces Siwok vio mujer

18 b. ella llega / mujer dice yo

$19 \mathrm{~b}$. vengo traigo plato yo ponga

20 b. miel. / dice Siwok « ¿[Eres] sola?»

A esta altura, es también muy difícil leer el texto wichí, no tanto porque su notación no sea fonológica ${ }^{17}$, sino más bien por la falta de puntuación y por el modo aleatorio de separar las «palabras ». Veamos, como un ejemplo sencillo, las dos anotaciones diferentes, en la misma línea 37 , del prefijo posesivo de 3 . $^{a}$ persona, $l \ddot{e}$-:

37 a. wet yamei le wet / lejcha akojej

Y luego otro ejemplo apenas más complejo, con la raíz verbal tamen, « causar », y su sufijo aplicativo - ej, en dos líneas contiguas, 102 y 103 :

102 a. yokw: ijcha: le tameni yeja

103 a. ochejwa wet elat le ta menej

15. Martínez Crovetto (1995, p. 95) registró que siwokw era también el nombre de otras especies de carpinteros de copete rojo: Coephloeus [sic] lineatus (en rigor, el género era Ceophloeus, y la especie hoy se llama Dryocopus lineatus), C. erythrops (hoy considerada una subespecie de D. lineatus), Neophloeotomus schulzii (hoy Dryocopus schulzi) (ver Remsen et al. 2016). Es decir, Martínez Crovetto afirmó que siwokw también nombraba al carpintero garganta estriada (D. lineatus) y al carpintero negro (D. schulzi). Sin embargo, el área de distribución actual de D. lineatus está por fuera del territorio wichí; y D. schulzi, cuya área de distribución sí comprende dicho territorio, es «muy escasa o difícil de ver » (véase Narosky y Yzurieta 2003). Mis colaboradores wichí desconocen a D. schulzi, pero eso no implica necesariamente que el dato de Martínez Crovetto sea falso; por eso, en algunos contextos, es mejor traducir siwokw por el zoónimo general « pájaro carpintero ».

16. Los corchetes de la línea 20 son de Métraux.

17. A diferencias de trabajos anteriores (por ejemplo, Métraux 1939), esta vez Métraux al menos sigue de cerca la ortografía de los misioneros anglicanos (ver Hunt 1937, 1940). Aunque sí es cierto que, al anotar las vocales nativas solamente con las cinco vocales españolas, se generan equívocos. 


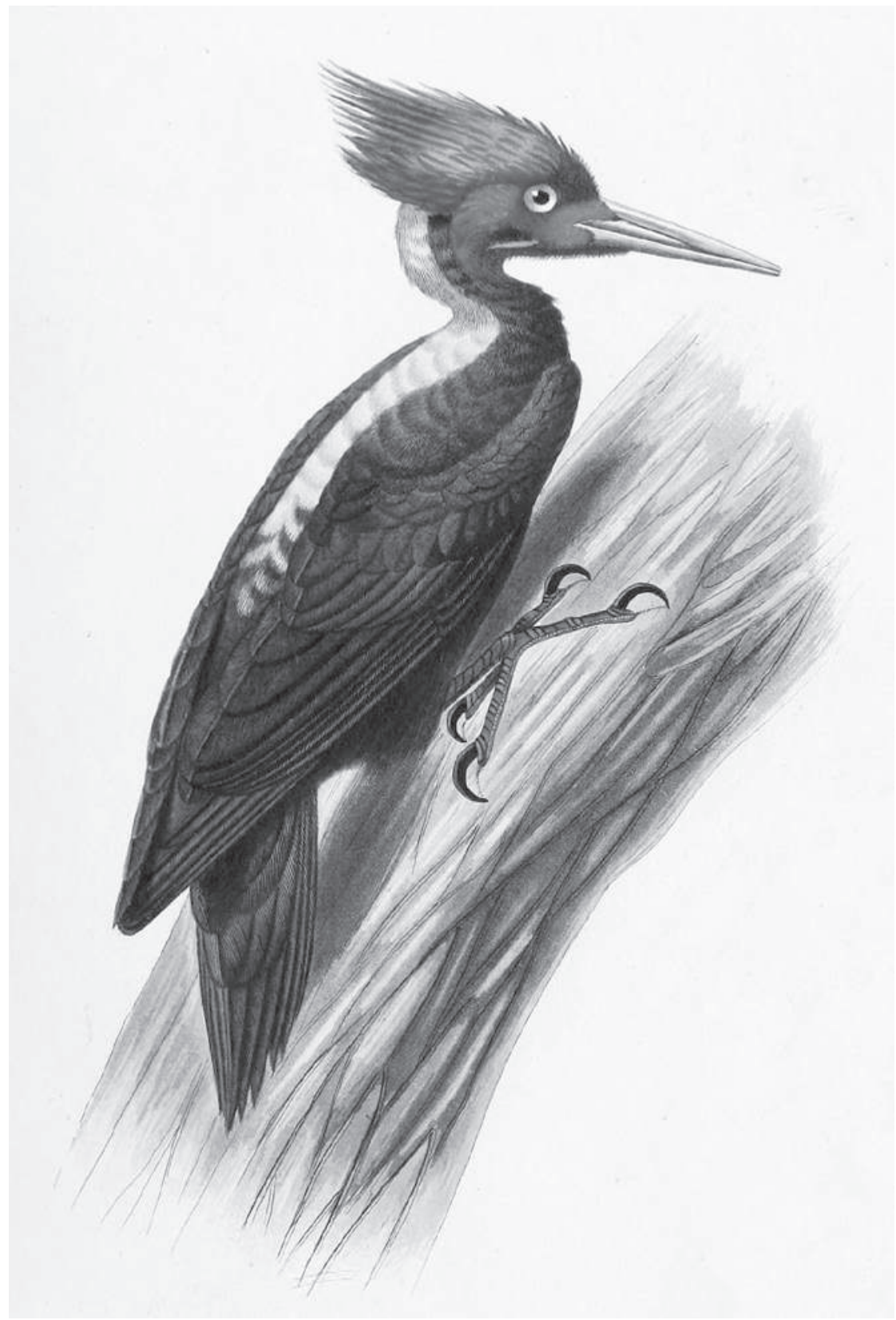

Fig. 4 - Dibujo del carpintero lomo blanco, Campephilus leucopogon, el siwokw de los wichís (= Picus atriventis, in Alcide d'Orbigny, Voyage dans l'Amérique méridionale, tomo IX, oiseaux, lámina 63). 
Tenemos, pues, un texto wichí anotado en terreno, extremadamente difícil de leer incluso para alguien que conozca la lengua, y un intento rudimentario de traducción. Es comprensible que Métraux jamás haya publicado los mitos de esta libreta. Sin embargo, apelando a mi conocimiento de la lengua y a las gramáticas y vocabularios publicados, me atreví a transliterar, analizar y traducir el primero de ellos, y el resultado es un texto rico, coherente y cohesivo. Como ejemplo del análisis realizado doy tan sólo siete líneas, de 37 a $43^{18}$, a fin de que el lector pueda comprobar los muchos cambios que debí introducir para acondicionar el texto ( $c f$. líneas $\langle\mathrm{a} »$ con $\langle\mathrm{c} »)$, la gran diferencia entre el rudimento de traducción de Métraux y mi traducción ( $c f$. líneas « $\mathrm{b} »$ con «e ») y, finalmente, el tipo de análisis gramatical que fundamenta mi propuesta de traducción.

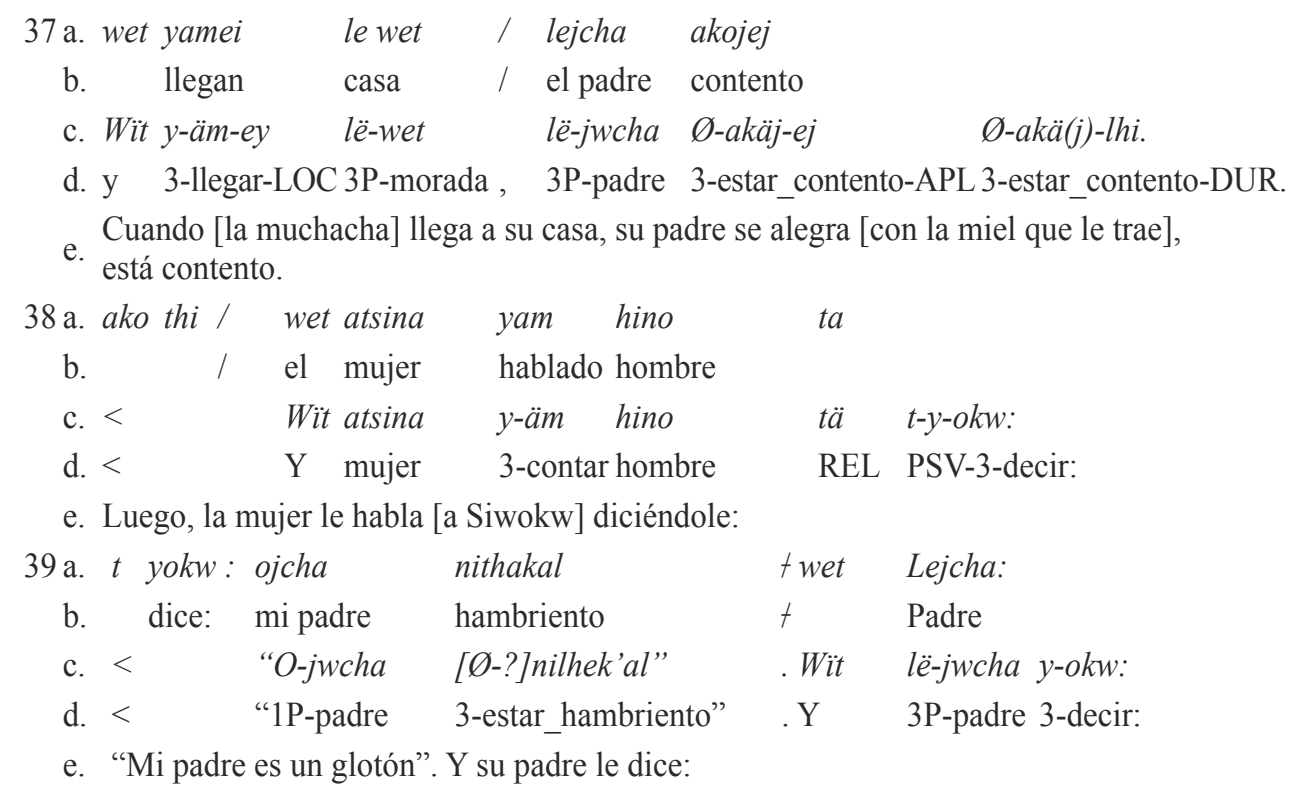

18. En las líneas c o d, el símbolo < indica que subió una parte de la línea a o b correspondiente. Los agregados entre corchetes son siempre míos y, además del uso indicado en la nota 14, introducen elementos que se deducen del « cotexto » y pretenden facilitar la lectura. En la línea c, el símbolo Ø- señala un morfema cero. He aquí el valor fonológico (y en algunos casos, también fonético) de mi alfabeto: $a / \mathrm{a} /, \ddot{a} / \mathrm{p} /, c h / \mathrm{k}^{\mathrm{y}} /, \mathrm{ch}^{\prime} / \mathrm{ky}^{2} /, e / \mathrm{e} /, \ddot{e}$ le/ [ə], $h / \mathrm{h} /, i / \mathrm{i} /, \ddot{i} / \mathrm{i} /[\mathrm{I}], j / \mathrm{x} /, j w / \mathrm{x}^{\mathrm{w}} /, k / \mathrm{k} /, k w / \mathrm{k}^{\mathrm{w}} /, k^{\prime} / \mathrm{k}^{2} /, l / 1 /, l h / 1 /, m / \mathrm{m} /, h m / \mathrm{m} /[\mathrm{m}], n$ $/ \mathrm{n} /, h n / \mathrm{n} /[\mathrm{n}], o / \mathrm{o} /, p / \mathrm{p} /, p h / \mathrm{p} /\left[\mathrm{p}^{\mathrm{h}}\right], p^{\prime} / \mathrm{p}^{2} /, s / \mathrm{s} /, t / \mathrm{t} /$, th $/ \mathrm{t} /\left[\mathrm{t}^{\mathrm{h}}\right], t^{\prime} / \mathrm{t}^{\mathrm{P}} /, t s / \mathrm{ts} /, \mathrm{ts}^{\prime} / \mathrm{ts}^{2} /, u / \mathrm{u} /$ $[\mathrm{u}], \ddot{u} / \mathrm{u} /$ que alterna con $/ \mathrm{i} /, w / \mathrm{w} /, y / \mathrm{j} /$. Y estas son las abreviaturas del glosado gramatical: 1P prefijo posesivo de $1 .{ }^{\mathrm{a}}$ persona, 3 prefijo verbal de $3 .{ }^{\mathrm{a}}$ persona, $3 \mathrm{P}$ prefijo posesivo de

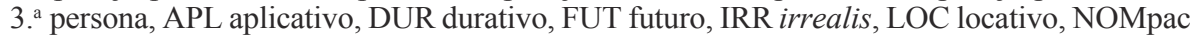
nominalizador pacientivo, PSV marcador de voz pasiva, REL relacionante, VOC vocativo. 


$\begin{array}{llllll}40 \text { a. yokw:[?] } & e & \text { yase } & \text { neche } & \text { othak } & \text { ihi } \\ \text { b. dice } & \text { mi hija, } & & \text { tengo } & \text { que come } \\ \text { c. }< & \text { "Uu y-äse, } & \text { nech'e } & \text { o-lhäk } & \varnothing \text {-i-hi; } \\ \text { d. }< & \text { "Sí VOC-hija, recién } & \text { 1P-comida } & \text { 3-existir-LOC; } \\ \text { e. "Sí mi hija, recién ahora tengo qué comer; } & & \end{array}$

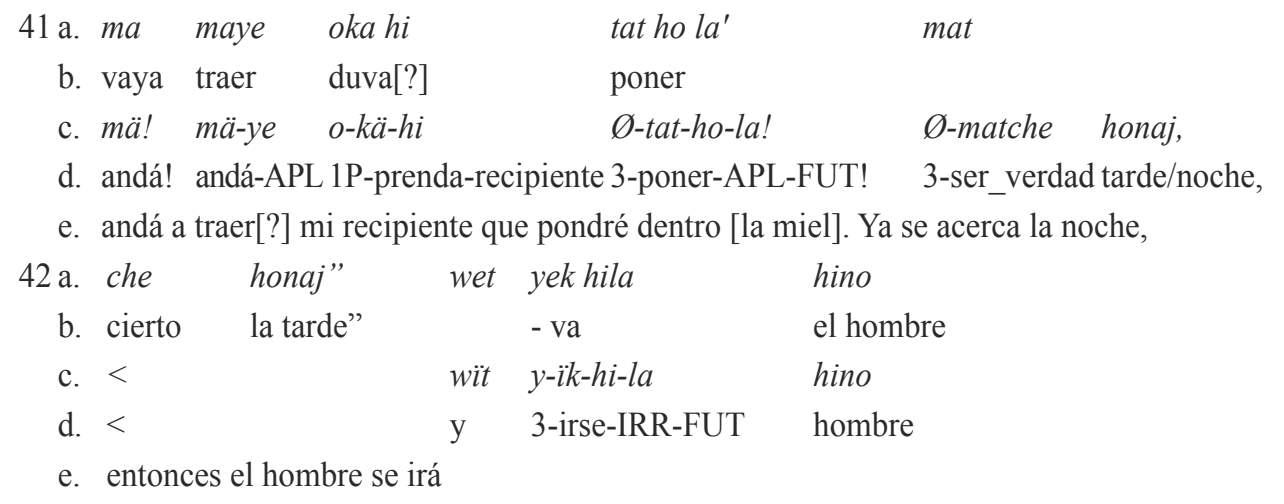

\begin{tabular}{|c|c|c|c|}
\hline 43 a. $i \quad$ ni hi hila & oni wik" & / atsina & yokw \\
\hline esperar & plataforma" & / mujer & dijo \\
\hline c. i-nijwi-hi-la & $o-n i j w i-k "$ & Atsina & $y$-okw: \\
\hline d. 3-esperar-IRR-FUT & 1P-esperar-NOMpac" & . Mujer & 3-decir: \\
\hline
\end{tabular}

El resultado final es el siguiente texto, que en aras de la brevedad presento sólo en dos columnas: a la izquierda, el texto wichí acondicionado, y a la derecha, mi traducción, que intencionalmente es bastante literal.

\begin{tabular}{|l|l|}
\hline Historia de Tokwi[?Ifwaj & Pájaro Carpintero y la hija de Sol \\
\hline $\begin{array}{l}\text { Ichep'ante hino tä Tokwaj wït häp hino } \\
\text { tä lhey Ijwala, wït t'ukwep'ante pinu. Wit } \\
\text { näm, wït lhäse inuphä wit yokw: }\end{array}$ & $\begin{array}{l}\text { Hubo una vez un hombre que [era] Tokwaj } \\
\text { Sol, que estaban buscando miel de yana } \\
\text { [Scaptotrigona jujuyensis]. Cuando [Sol] } \\
\text { llega [a su casa], su hija se levanta y le } \\
\text { dice: }\end{array}$ \\
\hline - Ijwcha kelhit! & $-¡$ Apúrate papá! \\
\hline Wï yämë lhäse: & Y [Sol] contesta a la hija: \\
\hline - Wït tä onäm wït lëlhaklhino. & - Ni bien llego y ya me estás molestando. \\
\hline Wit yämë lhäse wït yokw: & Entonces habla con su hija diciéndole: \\
\hline - Mä uk Siwokw! Ihän tä pinu-cha e $e$ & $-¡$ iAnda a buscar a Siwokw! iSíguelo que \\
weja[?]! & es un gran[?] melero! \\
\hline
\end{tabular}




\begin{tabular}{|c|c|}
\hline $\begin{array}{l}\text { Wit yïk atsina, tachuma lëpokw wit yoytho } \\
\text { lhey (hilu) wit yïkp'ante. }\end{array}$ & $\begin{array}{l}\text { Entonces la mujer se va, toma su } \\
\text { cantimplora y la mete en su morral, y se va. }\end{array}$ \\
\hline $\begin{array}{l}\text { Atsina tayätsanë Sulaj-chänis wït tälhë, wït } \\
\text { yïk yahoyë Tokwaj wït yokw: }\end{array}$ & $\begin{array}{l}\text { La mujer llega a [donde está] Sulaj- } \\
\text { chänis [carpintero real común, Colaptes } \\
\text { melanolaimus] y le pregunta; [es decir,] } \\
\text { se va hasta donde [está] Tokwaj [bajo la } \\
\text { forma de Sulaj-chänis] y éste le dice: }\end{array}$ \\
\hline - Ache! Ohäpe Siwokw. & - ¡Ven! Yo soy Siwokw. \\
\hline Wit ihnyäj yokw: & Pero otros dicen: \\
\hline - Chanlhaye! Ahäpehit’ë Siwokw. & - ¡Déjala! Tú no eres Siwokw. \\
\hline Wit elh yokw: & Y otro le dice [a la muchacha]: \\
\hline $\begin{array}{l}\text { - Mä! Hän täjipa Siwokw wït tejwaji } \\
\text { tsemlhäkw. }\end{array}$ & $\begin{array}{l}\text { - ¡Anda! Sigue por allá, dicen que Siwokw } \\
\text { está en ese lugar donde hay un único } \\
\text { yuchán [Ceiba chodatii]. }\end{array}$ \\
\hline $\begin{array}{l}\text { Wit atsina nichäte. Wit Siwokw hiwen } \\
\text { atsina tä nichäte. Wit atsina yokw: }\end{array}$ & $\begin{array}{l}\text { Entonces la mujer alcanza aquel lugar. Y } \\
\text { Siwokw ve que llega la mujer. La mujer, } \\
\text { pues, le dice: }\end{array}$ \\
\hline $\begin{array}{l}\text { - Olhammathï[?], lhu! Chäj akähi otatho } \\
\text { pinu. }\end{array}$ & $\begin{array}{l}\text { - Acá estoy[?], ¡ven! Te traje un recipiente } \\
\text { para poner la miel de yana. }\end{array}$ \\
\hline Wit yokw: & Y [Siwokw] le pregunta: \\
\hline - Ha atalhamë? & - ¿Estás sola? \\
\hline Wit atsina yokw: & Y la mujer responde: \\
\hline $\begin{array}{l}\text { - Uu, ojwcha [tä?] [wït?], [hän?] tä } \\
\text { onek[?] tä ot'uamche. }\end{array}$ & - Sí, mi padre me manda a buscarte. \\
\hline $\begin{array}{l}\text { - Witchïkmatiwoye ajwcha, wït-[Siwokw] } \\
\text { yokw - ani[?] ojwaj ayï halämathï. Wit ha } \\
\text { lëtilhäjmathï inät? Olhammathï tä ochim, } \\
\text { wït ha lëchäjmathi alhunti? }\end{array}$ & $\begin{array}{l}\text { - Si es verdad que tu padre hizo eso - dice } \\
\text { Siwokw -, entonces [?] espérame un rato } \\
\text { que termine de hachar este palo. ¿Y has } \\
\text { traído agua? Tengo sed, ¿qué cargas en } \\
\text { tu bolsa? }\end{array}$ \\
\hline Atsina yokw: & La mujer le contesta: \\
\hline - Uu, ochäjmathï. & - Sí, traje. \\
\hline $\begin{array}{l}\text { - Wit nech'e nojw pinu të ihi tsemlhäkw, } \\
\text { wït nech'e onuchä; wït pajche wak('a) } \\
\text { lh(h)at ajwi wït ayi ayïj owot'elak-wetë. } \\
\text { - Yokw: - Huwa elh tsäyho alhunti! ¿Ha } \\
\text { lë(i)hi[?]? Tat täjna pajche lë(i)hi[?]Wï } \\
\text { pinu-hi wujw të iyej tsemlhäkw. Wit huwa! } \\
\text { Kelwto! Lë(i)hi[?],nekhena! }\end{array}$ & $\begin{array}{l}\text { - Cuando se acabe la miel de yana que } \\
\text { hay dentro del yuchán [- dice Siwokw -], } \\
\text { recién entonces bajaré; pero anda ya } \\
\text { preparando tu pañuelo mientras yo [?] } \\
\text { descanso un momento. - [Y le] dice: } \\
\text { - Mete en [?] otro, ¡vierte en tu bolsa! } \\
\text { ¿Cabe?[?] ¿Cupo lo que pusiste?[?] El } \\
\text { panal que está en este yuchán es grande } \\
\text { [- dice Siwokw -]. ¡Carga! ¡Apurémonos! } \\
\text { ¡Mete y vámonos[?]! }\end{array}$ \\
\hline
\end{tabular}




\begin{tabular}{|c|c|}
\hline - Nech'e ojwcha hiwenla hat'es! & $\begin{array}{l}\text { - ¡Ahora mi padre tendrá aloja! [- dice } \\
\text { la muchacha.] }\end{array}$ \\
\hline $\begin{array}{l}\text { Wit yämey lëwet, lëjwcha akäjej akä(j)lhi. } \\
\text { Wit atsina yäm hino tä tyokw: }\end{array}$ & $\begin{array}{l}\text { Cuando [ella] llega a su casa, su padre se } \\
\text { alegra [con la miel], está contento. Y la } \\
\text { mujer habla [a Siwokw] diciéndole: }\end{array}$ \\
\hline - Ojwcha nilhek'al. & $\begin{array}{l}\text { - Mi padre está hambriento [porque es } \\
\text { un glotón]. }\end{array}$ \\
\hline Wit lëjwcha yokw: & Y su padre le dice: \\
\hline $\begin{array}{l}\text { - Uu, yäse, nech'e olhäk ihi. Mä, mäye } \\
\text { okä-hi tathola! Matche honaj, wït yïkhila } \\
\text { hino inijwihila onijwik. }\end{array}$ & $\begin{array}{l}\text { - Sí, hija mía, recién ahora tengo qué } \\
\text { comer. ¡Ve a traer[?] mi recipiente que } \\
\text { pondré [la miel] dentro! Ya se acerca } \\
\text { la noche, entonces el hombre se irá y } \\
\text { aguardará en [la plataforma que es] mi } \\
\text { apostadero. }\end{array}$ \\
\hline Atsina yokw: & La mujer le dice [a Siwokw]: \\
\hline $\begin{array}{l}\text { - Mä tä lhek! Yëjlëmäla tsi... häp tä hayäj } \\
\text { lhäti tä achename, wït chïk lëlätla, wït } \\
\text { amajejë! Wit tiyäjla lëtacho wït lëlänla } \\
\text { hayäj, matche yil wït tapila. Wit chïk } \\
\text { lënäm wïtyäyej hat'es, lëtetsanëla ojwcha } \\
\text { wït lëlhak'an nilapetsi häp tä wujw tä } \\
\text { nilhek'al. Wit lajitelha ach'ejwa wit } \\
\text { ojwcha ayahumin. Wit lëwenla t'ekëyaj } \\
\text { chïk kanowayëyë. Wit lhenoyej; chik } \\
\text { lhenoyej wït ojwcha aihumin tä apinu-cha. }\end{array}$ & $\begin{array}{l}\text { - ¡Ve, anda! [Pero] no duermas porque... } \\
\text { porque en el bebedero del jaguara al que te } \\
\text { manda, si oyeses [al jaguar], iprotégete! } \\
\text { Y dispárele a la frente, entonces matarás } \\
\text { al jaguar, realmente estará muerto y } \\
\text { regresarás[?]. Y cuando llegues y tomes } \\
\text { aloja, mirarás a mi padre y al final[?] te } \\
\text { molestarás, porque es muy glotón. Pero no } \\
\text { hay otro cónyuge y mi padre te quiere. Y } \\
\text { si no tienes miedo, verás su forma [voraz] } \\
\text { de comer. Entonces quédate conmigo; a mi } \\
\text { padre le gustará[?] que te quedes conmigo } \\
\text { porque eres melero. }\end{array}$ \\
\hline Wit yämep'ante lhäse wït yokw: & Y [Sol] le habló a su hija diciéndole: \\
\hline - Yäse, hach'ejwa ninekchujwi okänek. & - Hija, que tu marido se lleve mi carnada. \\
\hline $\begin{array}{l}\text { Wit hino yikkchujwi lë[ka?]chäti-känek, } \\
\text { yahoho lëwumek tä wujw. Wit yen[?] mak } \\
\text { të ihi lëwumek k'a wahat. Wit atsina yokw: }\end{array}$ & $\begin{array}{l}\text { Así pues, el hombre parte con[?] la carnada } \\
\text { del suegro, se mete en una gran cañada }{ }^{\text {}} \text {. Y } \\
\text { [?] lo que hay en esa cañada no es un pez. } \\
\text { Pero la mujer le dice[, es decir, le había } \\
\text { dicho a Siwokw]: }\end{array}$ \\
\hline
\end{tabular}

a. Hayäj lhäti, « bebedero del jaguar », podría tratarse de un topónimo.

b. Lëwumek, que literalmente significa « su desecho » y que por simplicidad traduzco con el regionalismo « cañada », refiere a un meandro abandonado donde suele haber agua.

c. Una traducción más literal de la frase wït häpkhilak ijwalas nitäkw tä lëlähnen sería «y pasarán muchos días que mates »; pero hay un uso figurado del verbo -län, « matar », que refiere al paso del tiempo. Por ejemplo, ilän otsentaylos nekchämis, « hace ya ochenta y dos años » (ver Montani y Juárez 2016, p. 48-49). 


\begin{abstract}
- Mä tä lhek! Yëjtohnila anichäte wït chïk lëtäjwelej chïk wujwche; wï ma tohnila. Chïk niwujwache, wit tohnila. Wit lëlänla chïk niwujwache. Wit kanyaamej, wï amej amej yejtatachä, wït häpkhilak ijwalas nitäkw tä lëlähnen, wït häpkhila lëtäpil. Wit lënäm, wït oyïkhilaamche te[?] la[?] ojwcha yïkhiyela ihnyäj itatlape lëwute, wït akäjhiyejlhila të hiwen lhäk tä wujw, häp tä lëlhaklhi ihi.
\end{abstract}

${ }_{-}$iVe, anda! [Pero] no vayas a sacar tu anzuelo[, tu línea de pesca,] si te das cuenta de que es [algo] grande; no[?] vayas a sacarlo. [En cambio,] si es [algo] chico, entonces sácalo. Es decir, lo matarás si no es grande. Y prepárate, cuídate[?] de no arrojar [la línea], para que pases allí [?] muchos días ${ }^{\mathrm{c}}$, y luego regreses [al hogar]. Cuando vuelvas, me iré contigo e irá[?] también[?] mi padre con[?] otros que[?] cargarán sobre su animal de monta, y [tú] estarás contento de que [él] vea su mucha comida, porque [él, como es un glotón,] está afligido.

\begin{tabular}{|c|}
\hline Wit honaj elh yokw: \\
\hline - Yäse, hach'ejwa nihoho onijwik. \\
\hline Wit lëch'ejwa yokw: \\
\hline - Mä kaneja itsäwet! \\
\hline $\begin{array}{l}\text { Wit yahohop'ante tä lëka-chäti ichene } \\
\text { lënijwik. Wit ihip'ante tä yahoho tä honatsi } \\
\text { wït itsäwet nekey[?] inät: häpep'ante } \\
\text { iyela. Wit tiyäjp'ante wït tiyäjp'ante wit } \\
\text { taji lëtacho wït yil, ilän. }\end{array}$ \\
\hline
\end{tabular}
Y otra tarde [Sol] le dice [a su muchacha]: - Hija, que tu marido se vaya a mi apostadero.

Y su esposa le dice [a Siwokw]:

- ¡Anda a atrapar[?] un animal!

Entonces [Siwokw] se metió en el apostadero donde lo enviaba su suegro. Y era ya de noche cuando[?] se subió [a la plataforma] y un animal se dirigió hacia el agua: era un tapir [Tapirus terrestris]. [Siwokw] le disparó, le tiró [con la flecha] y le acertó en la frente y [el tapir] agonizó [y] murió.

Wit tajyämëp'ante wït inij(w)i, wït Y pasó un tiempo y [el hombre] esperaba, häpep'ante ch'iwase nekey inät wit äp taji lëtacho wït äp ilän. Wit talhamëp'ante nech'e yäpil; të ilän itsäwet tä wus, wit yäpley lë[ka-?]chäti. Wit lë[ka-?]chäti yikche ilhokej[?] lëwutey wït yämey wit isajen[?] wït ilahni itäj wït hip'o, yisej lësijtaj tä hip'o. Wit tujw wït yahämït ch'iwase; talhamë iyela të ichäja lëwet; wit tilhäjp'ante iyela tilhäja lëwet.

Wit yämho lëwet, tujw mälhtej tha nojw. Wit lhäse yokw: y un ciervo [Blastocerus dichotomus] vino al agua y [el hombre] otra vez le acertó en la frente y también lo mató. Cuando ya no hubo nada más, entonces emprendió el regreso; después de[?] matar grandes animales[?], regresó a lo de su suegro. Y su suegro se fue con todos[?] sus animales de monta[, sus caballos, y] cuando llegó [al apostadero], desollaron [los animales] y [Sol] encendió un fuego y puso a asar un costillar. Comió, pues, hasta que se terminó el ciervo; a su casa sólo llevó el tapir; cargó el tapir [y] lo llevó a su morada.

Cuando [Sol] llega a su sitio de vivienda, come e inmediatamente se termina todo. Su hija entonces le dice: 


\begin{tabular}{|c|c|}
\hline $\begin{array}{l}\text { - Ijwcha, lëtameniyeja och'ejwa, wït elat } \\
\text { lëtamenej och'ejwa. Wit olhakhi ihihila } \\
\text { wuj(w)pej(t')at tä äk häp am lëlhak'al } \\
\text { wït nojw. }\end{array}$ & $\begin{array}{l}\text { - Papá, perjudicarás a mi marido y quizá } \\
\text { lo hagas sufrir. Yo estoy afligida [porque } \\
\text { aunque] siempre haya mucha comida para } \\
\text { vos, estás [siempre] insatisfecho[?] y [la } \\
\text { comida] se agota. }\end{array}$ \\
\hline Wit $y$ & Entonces [Sol] le contesta: \\
\hline - Yäse, ach'eju & $\begin{array}{l}\text { - Hija, [que] tu marido vuelva[?] a mi } \\
\text { apostadero. }\end{array}$ \\
\hline Wit yik yahoho. Wit lëch'e & $\begin{array}{l}\text { Y [Siwokw] parte, se interna [en el monte]. } \\
\text { Pero su esposa le dice: }\end{array}$ \\
\hline $\begin{array}{l}\text { - Mä tä lhek! Tejpeja lëtohni anichäte. } \\
\text { Yahïnla tä niwujwache tä lhäyït wït häp } \\
\text { chïkpej(t')at[?] lëlän, wït chïk lhäyït tä } \\
\text { wujwche, wit ailänla. [Ta]lhamë ailänla } \\
\text { tä wujwche. }\end{array}$ & $\begin{array}{l}\text { - ¡Ve, anda! [Pero] no siempre[?] saques } \\
\text { tu anzuelo. Mirarás si es pequeño lo que } \\
\text { atrapas y que siempre lo puedas matar, } \\
\text { porque si atrapas [algo] grande, entonces } \\
\text { [eso] te matará. Únicamente el [bicho] } \\
\text { grande te matará. }\end{array}$ \\
\hline $\begin{array}{l}\text { Wit yäyïtp'ante tä wujwche wït itohnip'ante } \\
\text { lënichäte. Wit ilänp'an[te?] hino të itohni } \\
\text { lënichäte. }\end{array}$ & $\begin{array}{l}\text { Y [sucedió que el hombre] enganchó } \\
\text { [algo] grande y levantó la línea de pesca. } \\
\text { Entonces [el bicho] mató al hombre que } \\
\text { sacó la línea de pesca. }\end{array}$ \\
\hline $\begin{array}{l}\text { Wit ijwalap'ante wit nehmit näm; wit } \\
\text { lëch'ejwa yokw: }\end{array}$ & $\begin{array}{l}\text { Y pasaron lc } \\
\text { venía; entonc } \\
\text { su padre]: }\end{array}$ \\
\hline - Atsï tä mak ch & $\begin{array}{l}\text { - ¿Qué cosa habrá terminado con el hombre } \\
\text { en aquel lugar[?]? }\end{array}$ \\
\hline $\begin{array}{l}\text { Wit yïk të itamakche lhachïwwa. Wit } \\
\text { yämep'ante lëkänek, wit niweniyët'at } \\
\text { lhachïjwa. Ochäjot'at inät wït äp tachuma } \\
\text { halä wit itsänchujwi Lëwo. Itsänejchujwi } \\
\text { halä wït nilhokyëyë lhachijwa. Wit } \\
\text { äp yahäye Lëwo elh tä ijwache wit äp } \\
\text { itsänejchujwi halä, wit nech'e Ijwala } \\
\text { ilhoka lhachïwwa Siwokw. Wit Siwokw } \\
\text { tiyäja halä tä molhyejlini, wït nehmit nälej } \\
\text { chïk häpe noelh, wit höp tä siwokw lëcha } \\
\text { ichät, tsi häp lëchowejp'ante. }\end{array}$ & $\begin{array}{l}\text { Así pues, [Sol] va a constatar qué pasó con } \\
\text { su yerno. Llegó entonces al lugar donde } \\
\text { estaba su carnada, pero ahí no encontró a } \\
\text { su yerno. Sacó toda el agua [de la cañada] } \\
\text { y además agarró un palo y ensartó un } \\
\text { [monstruo] Lëwo [Arco Iris]. Le metió } \\
\text { el palo por dentro, pero no encontró a su } \\
\text { yerno. Se dirigió, pues, a otro Lëwo que } \\
\text { estaba al lado y también lo ensartó con } \\
\text { el palo, y recién entonces Sol dio con su } \\
\text { yerno Siwokw. Pero Siwokw salió volando } \\
\text { hasta un palo como aquel, pues ya no } \\
\text { era semejante a uno de nosotros[, a una } \\
\text { persona], y por eso el carpintero lomo } \\
\text { blanco [siwokw] [tiene] su [cabeza de] } \\
\text { color rojo, porque antes [fue una persona,] } \\
\text { tuvo alma. }\end{array}$ \\
\hline
\end{tabular}


¿De dónde sacó Métraux éste y los otros mitos del cuaderno? Debe quedar en claro que esta versión de « Pájaro Carpintero y la hija de Sol » es bien diferente de las otras dos que publicó en Mitos y cuentos... (Métraux 1939, p. 34-37). Además, los textos de Mitos y cuentos... fueron recogidos en 1933, estaban listos para ser publicados en $1937^{19}$ y aparecieron en Suecia en 1939, mientras que hay buenas razones para confiar en la fecha que figura en la libreta en cuestión: 1939. Sabemos que el estudio de la lengua wichí había estado entre los propósitos del viaje de aquel año: « Pretendo ir al Pilcomayo y establecerme [...] cerca de San Andrés », escribe Métraux en 1937 en su solicitud de beca a la Fundación Guggenheim, " [donde] trataré de dominar la lengua [wichí] » (cit. en Bilbao 2002, p. 85). Y en 1939, ya en San Andrés, tras días de profundo desasosiego, el 3 de mayo consignó en su diario: « Traduzco textos con Antonio que bosteza, y yo también » (Métraux 1978, p. 86). Efectivamente, en la primera página de la libreta figura el nombre de Antonio - y quizá incluso se trate de un esbozo incompleto de su genealogía. No debe pensarse, obviamente, que el suizo anotó las 49 páginas de la libreta en un solo día. En sus diarios no dejó registro del día 4, pero en una única entrada correspondiente a los días 5, 6 y 7, anotó: « No escribí nada en mi diario porque trabajé todo el día sin pensar en nada » (Métraux 1978, p. 86). Ahora bien, en una carta-informe enviada el 13 de enero de 1940 al presidente de la fundación, le comenta: «procedí a remontar el Pilcomayo hasta los matacos que están ubicados cerca de [...] San Andrés. [...] Para mi gran dolor [...] La mayoría de los indios había aceptado el cristianismo y había abandonado completamente sus viejas costumbres. [... Sin embargo,] pude convencer a algunos indios de que escribiesen mitos en su propia lengua y en el presente varios de ellos están ocupados en esta tarea $»^{20}$. ¿Esto quiere decir que la versión inicial de los mitos de esta libreta fue anotada por el propio Antonio? No podemos saberlo, pero en todo caso la letra de la libreta es de Métraux. Quizá se estuviera refiriendo a otros mitos que quedaron inéditos y hasta el momento se encuentran extraviados ${ }^{21}$.

¿Por qué Métraux registró mitos en wichí? Supongo, por un lado, que buscaba rectificar sus Mitos y cuentos... con un método que sabía adecuado. Ya en 1925, en un artículo temprano y programático, aunque con reservas y objeciones, había defendido la importancia de recoger textos en lenguas nativas y someterlos a un análisis lingüístico (Métraux 1988, p. 67-68). Además, ya había ensayado este

19. Véase la carta de Jules Henry a Ruth Benedict, 01/10/1937, Archives and Special Collections, Vassar College, Benedict, Ruth, box 29.5.

20. Carta de A. Métraux al Sr. Moe, 13/01/1940 (en Bilbao 2002, p. 93; corrijo en la cita unas pequeñas deficiencias de la traducción: « Matako » por « matacos », « lenguaje » por « lengua » y un error de concordancia).

21. En la misma época un indígena escribió una « mitología mataca », quizá bilingüe, que fue traducida al inglés por el misionero John Arnott (Córdoba 2015, p. 109). 
método, modestamente, con los chipayas (Métraux 1935b, 1973, p. 224-254) y los pilagás (Métraux 1937), y lo aplicaría después al créole haitiano ${ }^{22}$. Por otro lado, parece que pensaba dedicarse de una vez por todas al mundo ceremonial, religioso y mítico de los wichís, que según sus propias palabras era « más rico que el de los tobas $\gg »^{23}$. Pero entonces, ¿por qué dejó la tarea inconclusa? Como dice en sus diarios, su depresión frustró la estadía en el campo y una lengua que le resultaba demasiado difícil probablemente lo desalentón ${ }^{4}$.

¿Qué valor pueden tener los mitos que Métraux dejó inéditos en esta libreta? Sigamos con el ejemplo del mito que presenté. Hay al menos diecisiete versiones publicadas de la historia de « Pájaro Carpintero y la hija de Sol », de calidad y extensión muy variables ${ }^{25}$. ¿Es esta « nueva » versión irrelevante? No, y por varias razones. Primero, porque en relación con el conjunto narrativo, tiene la particularidad de demorarse en las fatigas que Sol le ocasiona a su yerno Siwokw. Y este aspecto no es menor, pues si se considera que la estrategia típica de la narrativa wichí es « pintar el peor de los panoramas » (Palmer 2005, p. 121), bien puede decirse que la versión que Métraux dejó inédita ofrece una interesante reflexión sobre el riesgo que entraña la uxorilocalidad: si un yerno habilidoso y bien predispuesto es abrumado por un suegro egoísta e insaciable, la alianza entre afines fracasa sin remedio.

Además, entre las versiones publicadas, sólo la de Antonio Tovar (1981, p. 105-111) y la de John Palmer (2005, p. 248-254) son bilingües. Entonces, dos nuevas razones vienen a potenciar la relevancia de la versión que tratamos. Por un lado, las versiones bilingües - y ésta especialmente - restituyen la preeminencia del diálogo en la mitología wichí, opacada en las versiones monolingües por la narración en tercera persona; o por decirlo de otro modo, devuelven al mito su verdadera naturaleza dramática, al tiempo que limpian el tinte novelesco infundido por las versiones recogidas en español. Por otro lado, las tres versiones bilingües constituyen documentos únicos de palabras y cosas que en muchos casos - como bien vaticinaba Métraux - van desapareciendo (por ejemplo, nombres de ciertos animales o artefactos). O más aún, permiten

22. Me refiero a los relatos y proverbios en criollo haitiano que aportó a la obra del lingüista Robert Hall 1953.

23. Carta de A. Métraux a Jules Henry, 30/03/1936, Jules Henry Papers, 1933-1959, University Archives, Washington University in St. Louis, serie 7, box 7, pilaga 002. Un juicio similar figura en Métraux 1939, p. 3-4.

24. Alcide d'Orbigny y Mingo de la Concepción habían tenido una apreciación semejante de la lengua wichí: extremadamente difícil e inaccesible (véase Alvarsson 1988, p. 2).

25. Alvarsson 1993, p. 234-238; Arancibia 1973, p. 77-80, 86-89; Barabás y Bartolomé 1979, p. 129-131; Braunstein 1974, p. 74; Dasso 1999, p. 100-103; Fock en Wilbert y Simoneau 1982, p. 136-139; Heredia y Magnani 1980, p. 48-50; Idoyaga Molina 1976, p. 48-49; Mashnshnek 1973, p. 124; Métraux 1939, p. 34-37; Palavecino 1940, p. 257-258; Palmer 2005, p. 248-254; Terán 1999, p. 98-99; Tovar 1981, p. 105-111. 
plantear el tipo de problemas histórico-difusionistas que interesaban al Métraux de la etapa chaqueña. Doy dos ejemplos. Cuando tuve ocasión de discutir con los wichís algunas de las líneas de la versión en cuestión, algunos jóvenes, incluso procedentes de San Andrés, desconocían que sulaj-chänis, que literalmente significa « testículo de oso bandera (Myrmecophaga tridactyla) ${ }^{26}$ », es en rigor el nombre de una especie de pájaro carpintero (carpintero real común, Colaptes melanolaimus), cuya forma adopta Tío Travieso en el mito. Además, en esta versión inédita y en la de Palmer, Sol despacha a su yerno hacia una cañada armándolo de un lënichäte, un término que hoy designa tanto «su línea de pesca » como « su anzuelo ». En la libreta Métraux lo traduce como « anzuelo »; y Palmer (2005, p. 253), por su parte, como « anzuelo enorme ». Nordenskiöld (1920, p. 44-45) mencionó que los chiriguanos y chanés conocían un anzuelo precolombino, difundido probablemente desde los Andes, pero que yo recuerde ni él ni nadie indicó que los wichís hayan tenido anzuelos antes del contacto con los blancos. Algunos de los wichís de Los Baldes (departamento Rivadavia, provincia de Salta), sin embargo, recuerdan que sus abuelos usaban un lënichäte de madera de " escayante » (Mimozyganthus carinatus) para atrapar yacarés (Caiman latirostris chacoensis y C. crocodilus yacare). Si tenemos en cuenta que en el mito el lënichäte sirve para cazar monstruos Arco Iris, que, como dijo un informante de Métraux (1939, p. 36), « son como yacarés ", ¿de qué tipo de anzuelo estamos hablando? ¿De metal, europeo, o de un antiguo anzuelo indígena hasta el momento indocumentado? Hay que decir, como última razón, que estos relatos inéditos son por ahora los mitos escritos en wichí más antiguos que conocemos.

En la etnografía wichí de Métraux, pues, no sólo la lengua y los artefactos ameritan una relectura ${ }^{27}$. Sin duda elijo revisar estos temas por un interés personal, pero también porque creo que tal vez pongan en evidencia aspectos más generales de su obra chaqueña. Primero, la profunda impronta que le había dejado el americanismo de Nordenskiöld y Cooper, tan interesado por los objetos indígenas. Segundo, la importancia programática que el suizo otorgaba a la recolección de material en lengua indígena, que en el caso wichí tuvo un desarrollo paulatino que fue de las palabras sueltas en idioma indígena a los mitos en wichí que dejó inéditos en sus libretas. Por último, la sospecha de que

26. En las variedades de la lengua que mejor conozco, es más común llamarlo ayu-chänis, « testículo de oso hormiguero ». Ayu significa, literalmente, « tu punta » (de $a$-, prefijo

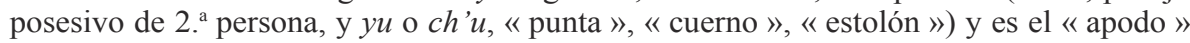
del oso bandera y del oso melero (Tamandua tetradactyla), aunque en este caso particular, el nombre del pájaro está inspirado en la forma de los testículo del primero. Ayu forma parte de un repertorio bastante amplio de zoónimos « suplentes » de los nombres « verdaderos » de los animales, construidos mediante mecanismos morfológicos y semánticos semejantes (Montani 2013, p. 84-86).

27. Véase, por ejemplo, Palmer 2013. 
para el «neurasténico » Métraux (1978), la recolección de cosas y palabras implicaba « una especie de sosiego » durante el trabajo de campo. Sosiego relativo, que a su modo habilitó una etnografía wichí pionera, excepcional y perdurable; pero también sosiego parcial, precario, supletorio, que nos dejó una obra parcialmente inédita e inconclusa, que - espero haber mostrado - vale la pena revisar y continuar. *

* Manuscrit reçu en janvier 2016, accepté pour publication en juin 2016.

Agradecimientos - Estoy muy agradecido con Lorena Córdoba, Federico Bossert, Dean Rogers, Sophie Assal y Miranda Rectenwald; no podría haber escrito este artículo sin los documentos que me facilitaron. También lo estoy con Diego Villar, Isabelle Combès, M. Eugenia Montani, Pastor Arenas y dos evaluadores anónimos $\operatorname{del} J S A$, que de maneras diversas contribuyeron con este trabajo.

\section{Referencias citadas}

Alvarsson Jan-Åke

1988, The Mataco of the Gran Chaco. An ethnographic account of change and continuity in Mataco socio-economic organization, Academiae Upsaliensis (Acta Universitatis Upsaliensis, Uppsala Studies in Cultural Anthropology, 11), Uppsala.

1993, Yo soy weenhayek. Una monografía breve de los Mataco-Noctenes de Bolivia, Museo Nacional de Etnografía y Folklore, La Paz.

2012, Etnografía 'weenhayek, vol. 3. Belleza y utilidad - La cultura material, Uppsala universitet (Dissertations and Documents in Cultural Anthropology, 13), Uppsala.

Arancibia Ubén G.

1973, Vida y mitos del mundo mataco, Depalma, Buenos Aires.

AREnAs Pastor

2003, Etnografía y Alimentación entre los Toba-Ñachilamole\#ek y Wichi-Lhuku'tas del Chaco central (Argentina), el autor, Buenos Aires.

Arenas Patricia

1998, «Alfred Métraux: Momentos de su paso por Argentina », Mundo de antes, 1, p. 121-145.

Barabás Alicia M. y Miguel Bartolomé

1979, « Un testimonio mítico de los mataco », Journal de la société des américanistes, 66, p. 125-131.

BiLbao Santiago A.

2002, Alfred Métraux en la Argentina: Infortunios de un antropólogo afortunado, Comala.com/La Galaxia, Caracas.

BING Fernande

1964, « Entretiens avec Alfred Métraux », L’Homme, 4 (2), p. 20-32.

Bossert Federico y Diego Villar

2007, « La etnología chiriguano de Alfred Métraux », Journal de la société des américanistes, 93 (1), p. 127-166. 
BRAUNSTEIN José A.

1974, « Matrimonio y familia entre los mataco », Cuadernos franciscanos, 35, p. 72-79. CóRDOBA Lorena

2015, « Etnógrafo-misionero, misionero-etnógrafo: Alfred Métraux y John Arnott», Boletín americanista, 70, p. 95-112.

DAsso María Cristina

1999, La máscara cultural, Ciudad Argentina, Buenos Aires.

GonZALo Juan Ángel

1998, La cultura material de los matacos (mataco-maka) del Chaco central, CAEA, Buenos Aires.

Hall Robert A. Jr.

1953, Haitian Creole: Grammar, Texts, Vocabulary, American Folklore Society, Filadelfia. Heredia Luis Domingo y Héctor R. MAGnANi

1980, « Takjwaj, héroe cultural de los mataco, en algunos relatos míticos », Publicaciones del Instituto de Antropología, 35, p. 41-57.

HunT Richard J.

1937, Mataco-English and English-Mataco Dictionary, [s. e.] (Ethnological Studies, 5), Gotemburgo.

1940, Mataco Grammar, Instituto de Antropología de la Universidad Nacional de Tucumán, San Miguel de Tucumán.

Idoyaga Molina Anatilde

1976, « Matrimonio y pasión amorosa entre los mataco », Scripta Ethnologica, 4 (1), p. 46-67.

LÉvi-STRAuss Claude

1971, Mitológicas II. De la miel a las cenizas, Fondo de Cultura Económica, México.

Martínez Crovetto Raúl N.

1995, Zoonimia y etnozoología de los pilagá, toba, mocoví, mataco y vilela, FFyL, Universidad de Buenos Aires, Buenos Aires.

Mashnshnek Celia Olga

1973, « Seres potentes y héroes míticos de los mataco del Chaco central », Scripta Ethnologica, 1, p. 105-154.

MÉTRAuX Alfred

1928, La civilisation matérielle des tribus Tupi-Guarani, Paul Geuthner, Paris.

1929a, « Deux anciens textes peu connus concernant l'institution du potlatch en Floride et dans le Chaco », Journal de la société des américanistes, 21 (2), p. 417.

1929b, «Le souvenir d'Erland Nordenskiöld dans le Chaco », Journal de la société des américanistes, 21 (2), p. 436-437.

1930, «Études sur la civilisation des Indiens Chiriguano », Revista del Instituto de Etnología de la Universidad Nacional de Tucumán, 1, p. 295-493.

1931, «La mujer en las sociedades primitivas », Azul: Revista de ciencias y letras, 10, p. 121-139.

1933a, « Nouvelles de la mission A. Métraux », Journal de la société des américanistes, 25 (1), p. 203-205. 
1933b, «La obra de las Misiones inglesas en el Chaco », Journal de la société des américanistes, 25 (1), p. 205-209.

1935a, «El universo y la naturaleza en las representaciones míticas de dos tribus salvajes de la República Argentina », Revista del Instituto de Etnología de la Universidad Nacional de Tucumán, 3, p. 131-144.

1935b, « Contribution à l'ethnographie et à la linguistique des Indiens Uro d'Ancoaqui (Bolivie) », Journal de la société des américanistes, 27 (1), p. 75-110.

1937, « Études d'ethnographie Toba-Pilaga (Gran Chaco)», Anthropos, 32 (3/4), p. 171-194, 378-401.

1939, « Myths and tales of the Matako Indians (The Gran Chaco, Argentina) », Etnologiska Studier, 9, p. 1-127.

1943, " Suicide Among the Matako of the Gran Chaco », América indígena, 3 (3), p. 199-209.

1944a, "Nota etnográfica sobre los indios mataco del Gran Chaco Argentino ", Relaciones de la Sociedad Argentina de Antropología, 4, p. 7-18.

1944b, «Estudios de etnografía chaquense », Anales del Instituto de Etnografía Americana, 5, p. 263-314.

1946, « Ethnography of the Chaco », in Julian Steward (ed.), Handbook of South American Indians, vol. 1. The Marginal Tribes, Smithsonian Institution, Washington, p. 197-370.

1973, Religión y magias indígenas de América del Sur, Aguilar, Madrid.

1978, Itinéraires, 1. Carnets de notes et journaux de voyage (1935-1953), Payot, Paris. 1988 [1925], « De la méthode dans les recherches ethnographiques », Gradhiva, 5, p. $57-71$.

MONTANi Rodrigo

2012, El mundo de las cosas entre los wichís del Gran Chaco. Un ensayo etnolingüístico, tesis de doctorado, Universidad Nacional de Córdoba, Córdoba.

2013, «Los bolsos enlazados de los wichís: etnografía de un agente ergológico », Suplemento antropológico, 48 (2), p. 7-144.

MonTANI Rodrigo y Gerardo JuÁREZ

2016, Ijwalas ta pajche: Mahnyay ta iyejen p'ante wichi ta ihi Muliyus, San Patlisyu lhoya Kale-hi/Los dias del pasado: Historias de los wichis de Morillo, San Patricio y Los Baldes, La Marmosa/Centro de Investigaciones Históricas y Antropológicas/Universidad Nacional de Córdoba, Córdoba.

Narosky Tito y Darío Yzurieta

2003, Guía para la identificación de las aves de Argentina y Uruguay, Vázquez Mazzini, Buenos Aires.

NORDENSKIÖLD Erland

1920, The changes in the material culture of two Indian tribes under the influence of New Surroundings, Comparative Ethnogeographical Studies, Gotemburgo.

Palavecino Enrique

1940, « Takjuaj, un personaje mitológico de los mataco », Revista del Museo de La Plata, Sección antropología, 1 (7), p. 245-270. 
PALMer John H.

2005, La buena voluntad wichí. Una espiritualidad indigena, Grupo de trabajo Ruta 81, Buenos Aires.

2013, «El suicidio wichí revisado », in Florencia Tola, Celeste Medrano, Lorena Cardin (eds), Gran Chaco: ontologías, poder, afectividad, Asociación Civil Rumbo Sur, Buenos Aires, p. 187-211.

Remsen James V. (Jr.), Juan I. Areta, Carlos D. Cadena, Santiago Claramunt, Alvaro Jaramillo, José F. Pacheco, Jorge Pérez-Emán, Mark B. Robbins, F. Gary Stiles, Douglas F. STOTZ y Kevin J. ZimmeR

2016, "A classification of the bird species of South America. American Ornithologists'Union », http://www.museum.lsu.edu/ Remsen/SACCBaseline. htm, consultado el 20/07/2016.

RiviÈRE Peter

2010, "Alfred Métraux: empiricist and romanticist », in Robert Parkin, Anne de Sales (eds), Out of the study and into the field. Ethnographic theory and practice in French anthropology, Berghahn Books, Nueva York/Oxford, p. 151-170.

TERÁN Buenaventura (compilación, prólogos y notas de)

1999, El ciclo de Tokjuaj y otros mitos de los wichís, Ediciones del Sol, Buenos Aires.

Tovar Antonio

1981, Relatos y diálogos de los matacos (Chaco argentino occidental). Seguidos de una gramática de su lengua, Ediciones Cultura Hispánica del Instituto de Cooperación Iberoamericana, Madrid.

WaGLey Charles

1964, « Alfred Métraux 1902-1963 », American anthropologist, 66 (3), p. 603-613.

Wilbert Johannes y Karin Simoneau (eds)

1982, Folk Literature of the Mataco Indians, University of California, Los Angeles. 
